Opinion

\title{
Environment, Geography, Geoecology
}

\author{
Vladimir A Gorbanyov* \\ Moscow State Institute of International Relations, Russia
}

\section{Opinion}

The environment in the broadest sense of the word is the sphere that is around us, the sphere in which we live, with which we interact on a daily basis, and which directly affects our development and our future. The concept of the environment emerged in the middle of the $19^{\text {th }}$ century. In the depths of biology. German zoologist E. Haeckel first defined ecology as the biological science of the relationship of organisms with the environment. At the same time, he understood the environment as a combination of living and inanimate elements of nature.

An invaluable contribution to the theory of human-environmental interaction was made by the American geographer J.P. Marsh, who wrote that nature takes revenge on man for ill-considered actions, for violating its natural balance, and at the same time emphasized that human activity is not only a geological, but also a geographic transforming force. In the USSR, after World War II, problems related to the interaction of the natural and social sciences were recognized as a pseudoscientific direction, as a result of which the problems concerning the study of the interaction of the environment and society fell out of sight of domestic scientists. As a result, the USSR lagged behind the West in this matter.

In our country, after a long hiatus in the mid-1960's. The outstanding Soviet geographer V.A. Anuchin, who was subjected to crushing criticism from most of his colleagues who adhered to conservative views about the impossibility of combining the social and natural sciences. The term "environment" became widespread in the 70s. last century after the International Conference on the Environment, held in Stockholm in 1972. The most important conclusion reached at the conference is the recognition of the inextricable link between a safe environment and socio-economic development. The main conclusion is that "the environment is the place of our life, and development is our actions to improve our well-being in it. Both of these concepts are inseparable. "

In this regard, we can conclude that the environment is the result of the interaction of three spheres: physical (or natural), anthropogenic (economic) and social, i.e. spheres of public relations. In short, the environment is a part of nature with which society directly interacts at this stage of its development. The environment is not only our cozy home, It can also carry threats, which can also be local in nature. The main hazard is determined by the limiting capabilities of the environment; it is not even a shortage of natural resources or environmental degradation that is critical, but the exponentially expanding pressure of our civilization on the environment. The environment will degrade until the cause of degradation disappears - a civilization that has failed to normalize its impact on the environment. As already noted, the German zoologist Ernst G. Haeckel defined ecology as a biological science. She is still dealing with the problems of interaction of living things, including humans, with living and inanimate natural environment.

In the literature, one can often find the conclusion that in our time, ecology has outgrown the framework of E. Haeckel's definition and began to involve not only natural, but also social and economic (anthropogenic) spheres in the sphere of its interests. In our opinion, this is an incorrect approach. If ecology begins to deal with the issues of not only the interaction of a living organism with the natural, but also with the social and anthropogenic spheres, i.e. with the environment, it will no longer be ecology, but geographic ecology, or geo-ecology for short. Geographical science, possessing the methods of a comprehensive assessment of the most complex

\begin{tabular}{|l|l|}
\hline Quick Response Code: & *Corresponding author: Vladimir A Gorbanyov, Moscow State Institute of International Rela- \\
tions, ProspektVernadskogo, Moscow 119454, Russia \\
Received: 27 July, $2021 \quad$ Published: 19 October, 2021 \\
\hline
\end{tabular}


relationships that exist on Earth and are reflected on the earth's surface, in the last decade, at the turn of the millennium, turned out to be the closest to understanding the systemic essence of environmental problems that have arisen on Earth. In addition, having mastered the methods of cartographic analysis and geo information technologies, she was able to relate the identified environmental and other contradictions as accurately as possible in space.

Therefore, we can conclude that today it is not ecology that has expanded its boundaries, as some scientists argue, but ecologists began to "play in the geographical field," at the same time, ecology, as a biological science, remains so today. The following definition of geoecology seems to be the most optimal: this is a section of geography that studies the interaction of a person with his environment, as an interconnected system of physical (natural), anthropogenic (economic) and social spheres at different territorial levels. Geoecology is engaged in the development of an integral system of spatio-temporal analysis of the problems of the interaction of the environment with a living organism (man), the causes of their occurrence, territorial distribution and the methods of their classification, assessment and mapping arising from the analysis, as well as the determination of ways to solve geoecological problems. It can be concluded that in geoecology, the object of study is geoecosystems, and in ecology, ecosystems.

\section{Acknowledgements}

None.

\section{Conflicts of interest}

Author declares that there is no conflict of interest.

\section{Funding}

None. 